\title{
Chronic Tonsillitis: A Recent Histopathological Study
}

\author{
${ }^{1}$ Wail F Nasr, ${ }^{2}$ Samir S Sorour, ${ }^{3}$ Mohammed K Mobasher, ${ }^{4}$ Hesham R Abd El Aziz
}

\begin{abstract}
Objectives: The aim of this study is to assess the incidence of tonsillomycosis in chronic tonsillitis on histopathological basis post-tonsillectomy in children.
\end{abstract}

Study design: Cohort study.

Level of evidence: Level II.

Setting: Tertiary University Hospital, Department of Otorhinolaryngology.

Materials and methods: This study included 75 cases of children suffering from chronic tonsillitis (43 females and 32 males). On assessment of the clinical condition of the children with history taking, clinical examination, and preoperative investigation, post-tonsillectomy tonsils are placed in a separate container in $10 \%$ formol saline, and then are sent for histopathological examination using hematoxylin and eosin and periodic acid-Schiff (PAC).

Results: The obtained result had $31.3 \%$ of tonsils (47/150) with histopathological evidence of fungal invasion of tonsillar tissue with immune reaction and the presence of chronic inflammatory cells. After statistical analysis of the collected crude data, we found that results have come in accordance with previous studies.

Conclusion: Tonsillomycosis is a cause of chronic tonsillitis. Haphazard use of antibiotics and dental caries has a significant predisposing role in tonsillomycosis. Neutropenia can be considered as an indicator for tonsillomycosis. It is considerable in hypertrophic tonsils.

Keywords: Chronic tonsillitis, Neutropenia, Tonsillomycosis.

How to cite this article: Nasr WF, Sorour SS, Mobasher MK, Abd El Aziz HR. Chronic Tonsillitis: A Recent Histopathological Study. Int J Otorhinolaryngol Clin 2016;8(1):1-5.

Source of support: Nil

Conflict of interest: None

\section{INTRODUCTION}

In a healthy child, infection is typically self-limited, although latency is usually established, rather than

\footnotetext{
${ }^{1,4}$ Associate Professor, ${ }^{2,3}$ Professor

${ }^{1-3}$ Department of Otorhinolaryngology and Head and Neck Surgery, Faculty of Medicine, Zagazig University, Zagazig, Egypt

${ }^{4}$ Department of Pathology, Faculty of Medicine, Zagazig University, Zagazig, Egypt
}

Corresponding Author: Wail F Nasr, Associate Professor Department of Otorhinolaryngology and Head and Neck Surgery Faculty of Medicine, Zagazig University, Zagazig, Egypt, Phone: +20552303264, e-mail: wail.fayez@yahoo.com elimination. Reactivation of latent infection may subsequently occur if the infected individual becomes immunosuppressed. The deep mycosis can affect individuals of all races with no racial predilection, both sexes, and individuals of all ages, although they are more common in adults than in children. Elderly people have increased risk, although this mycosis is frequently secondary to impaired immunity. Mycosis is a common opportunistic fungal infection of the oral cavity, oropharynx, and corners of the mouth. It is presented in a commensal state and has been easily shifted from commensally state to pathogenic state. Risk factors for the development of pathogenic form include local and systemic factors. Local factors affect or alter the ecology of the region due to topically delivered drugs (corticosteroids), xerostomia (with loss or diminution of saliva's protective function), passive smoking, and dental problems that favor establishment of infection. Children usually have some serious immune or metabolic defect, or have a systemic condition, such as poorly controlled diabetes mellitus (DM) or immunosuppressive condition., ${ }^{1,2}$

Common presentation of tonsillomycosis includes: red and/or swollen tonsils, white or yellow patches on the tonsils, tender, stiff, and/or swollen neck, sore throat, painful or difficult swallowing, cough, headache, sore eyes, body aches, otalgia, fever, chills, and nasal congestion. ${ }^{3}$ Tonsillomycosis possibly causes tonsillar hypertrophy causing variable degrees of upper airway obstruction. ${ }^{4}$ Tonsillectomy is the definite treatment of tonsillomycosis.

\section{MATERIALS AND METHODS}

This study was approved by the IRB Zagazig University, and a prospective study was carried out on 75 child patients ( 32 males and 43 females) complaining from chronic tonsillitis and 15 healthy children $(9$ males and 6 females) complaining from obstructive sleep apnea (OSA) and snoring, with no history of chronic tonsillitis (control group). All patients and control group presented at the Otorhinolaryngology Outpatient Clinic of Zagazig University Hospitals, Egypt between December 2012 and May 2014. The patients ages were between 4-12 years old and were examined for exclusion of the immunocompromised diseases as DM, long chronic illness as renal failure or hepatic failure, cases with viral infection with 
no chronic criteria and patients under chemotherapy were also excluded. The following data were collected from the included children after general examination: Age, sex, indication for surgery, presenting symptoms, tonsil size, and tonsil asymmetry. Tonsillectomy was performed with dissection or bipolar diathermy. Material constitutes 150 specimens of tonsillar tissue taken posttonsillectomy from 75 children complaining of chronic tonsillitis and 30 specimens of tonsillar tissue taken posttonsillectomy from 15 children complaining of OSA. The size of the tonsils is rapidly measured postoperatively by a ruler (length $\times$ width). The bisected tonsils were immediately preserved in $10 \%$ formol saline solution in separate bottles. The tonsils were collected from the otorhinolaryngology operative theatre in Zagazig University Hospital, Egypt, and then were sent to pathology unit as they were dehydrated, embedded, and cut at 4 to 5 micron thick by routine methods. The sections were stained with hematoxylin and eosin (H\&E) and periodic acid-Schiff (PAS) for histopathological examination. All the specimens were fixed in $10 \%$ formol saline for 24 hours, washed, then exposed to serial concentrations of ethyl alcohol, ended by absolute alcohol (for complete dehydration). Specimens were cleared in xylene and embedded in paraffin at $56^{\circ} \mathrm{C}$ in hot air oven for 24 hours. Paraffin bees wax tissue blocks were prepared for sectioning at $4 \mu \mathrm{m}$ thicknesses by slide microtome. The obtained tissue sections were collected on glass slides, deparaffinized, and stained with H\&E. The assessment of each tissue sample included evaluation of mucosal surfaces, crypts, and associated lymphoid tissue. All slides were re-evaluated for the presence of cryptitis, active tonsillitis, and location of the fungus groups.

The obtained results were statistically analyzed by using Statistical Package for the Social Sciences (SPSS)
Table 1: Age and gender distributions

\begin{tabular}{lcc}
\hline \multicolumn{3}{c}{ Age distribution } \\
\hline \multicolumn{3}{c}{$n=75$} \\
\hline $\begin{array}{l}\text { Age (years) } \\
\text { Mean } \pm \text { SD (range) }\end{array}$ & $6.3 \pm 2.2(4-12)$ \\
\hline \multicolumn{3}{c}{ From table the mean age is 8 years } \\
\hline \multicolumn{3}{c}{ Gender distribution } \\
\hline Gender & No. & $\%$ \\
\hline Male & 32 & 42.7 \\
Female & 43 & 57.3 \\
\hline Total & 75 & 100 \\
\hline
\end{tabular}

No.: Number of patients

version 17. Data were expressed as mean $\pm \mathrm{SD}$ for qualitative variables, while number and percentage for categorical variables. Chi-square $\left(\chi^{2}\right)$ and Student's t-test were performed as appropriate. $p$-value $<0.05$ was considered statistically significant.

\section{RESULTS}

The obtained results of 75 children (43 males and 32 females) were demonstrated in the following tables and were divided into three types of data:

\section{Demographic Results}

Including personal data (such as age, gender) were represented statistically in Table 1.

\section{Factors associated with Fungal Infection}

The factors were represented statistically in Table 2.

\section{Laboratory Investigations and Tonsil Size Results}

In this type of data, a relation between tonsil size and investigatory data with fungal infections was shown in Tables 3 and 4 .

Table 2: Factors associated with fungal infection in chronic tonsillitis

\begin{tabular}{|c|c|c|c|c|c|c|}
\hline \multirow{2}{*}{$\begin{array}{l}\text { Factors } \\
\text { Age (years) }\end{array}$} & \multicolumn{2}{|c|}{ Without fungal infection } & \multicolumn{2}{|c|}{ With fungal infection } & \multirow[t]{2}{*}{$\chi^{2}$} & \multirow{2}{*}{$\begin{array}{l}p \text {-value } \\
0.9\end{array}$} \\
\hline & $6.2+$ & & 6.3 & & & \\
\hline \multirow[t]{2}{*}{ Mean + SD (range) } & $(5-8)$ & & $(4-1$ & & & NS \\
\hline & $\mathrm{T}=\mathrm{C}$ & & & & & \\
\hline Gender & No. & $\%$ & No. & $\%$ & & 0.8 \\
\hline Male & 22 & 68.75 & 10 & 31.25 & & NS \\
\hline \multirow[t]{2}{*}{ Female } & 29 & 67.4 & 14 & 32.6 & & \\
\hline & & & & & 0.03 & \\
\hline - Dental caries & No. & $\%$ & No. & $\%$ & & 0.029 \\
\hline Absent & 27 & 84.4 & 5 & 15.6 & & $\mathrm{~S}$ \\
\hline Present & 24 & 55.8 & 19 & 44.2 & & \\
\hline - No. of attacks of AT & No. & $\%$ & No. & $\%$ & & 0.02 \\
\hline$<5$ in 1 year & 26 & 81.3 & 6 & 18.3 & 0.8 & $\mathrm{~s}$ \\
\hline$>5$ in 1 year & 25 & 58.1 & 18 & 41.9 & & \\
\hline
\end{tabular}

AT: Acute tonsillitis; No.: Number of cases; NS: Nonsignificant; S: Significant; $\because$ : According to patient history. With chi-square equation and Student's t-test, relation between factors associated with fungal infection is nonsignificant $(p>0.05)$ and significant $(p<0.05)$ 
Table 3: Relation between size of tonsils and fungal infection

\begin{tabular}{lll}
\hline $\begin{array}{l}\text { Without fungal } \\
\text { infection (-ve) }\end{array}$ & $\begin{array}{l}\text { With fungal } \\
\text { infection (+ve) }\end{array}$ & p-value \\
\hline $2.96 \pm 2.47 \mathrm{~cm}$ & $4.8 \pm 2.2 \mathrm{~cm}$ & $0.04 \mathrm{~S}$ \\
\hline
\end{tabular}

With chi-square equation and Student's t-test, probability value revealed that hypertrophy of the tonsil is significant $(p<0.05)$ Incidence is significant in hypertrophic tonsils than atrophic tonsil

Table 4: Relation between fungal infection and neutropenia

\begin{tabular}{lllll}
\hline Neutropenia (preoperative & & & & \\
CBC in chronic tonsillitis) & No. & Percent & $\chi^{2}$ & $p$-value \\
\hline Without fungi & 11 & 21.56 & 3.92 & 0.04 \\
& & & & $\mathrm{~S}$
\end{tabular}

With fungi

$24 \quad 100.0$

No.: Number of patients. From investigation profile, preoperative complete blood count of our 75 patients revealed 35 of them show neutropenia (11/51 without fungal infection and 24/24 with fungal infection), so with chi-square equation and Student's t-test, relation between fungal infection and neutropenia is significant $(p<0.05)$ and represent $100 \%$

\section{Histopathological Results}

This study included 75 children subjected to histopathological examination after tonsillectomy (15 tonsils). A total of $31.3 \%$ of them ( 47 tonsils) were positive for fungal infection.

\section{Macroscopic Findings}

- All subjective groups showed tonsils that range from 0.5 to $7 \mathrm{~cm}$ in diameter with variable-sized crypts filled with cell debris and necrotic material on the surface of the tonsils except the control group that showed tonsils ranging from 3 to $4.7 \mathrm{~cm}$ in diameter with large size crypts without cell debris and necrotic material on the surface of the tonsils.

- A total of 135 tonsils (105 tonsils from the subjective group and 30 tonsils from the control group) were hypertrophied with a size ranging from 3.5 to $7 \mathrm{~cm}$ in diameter.

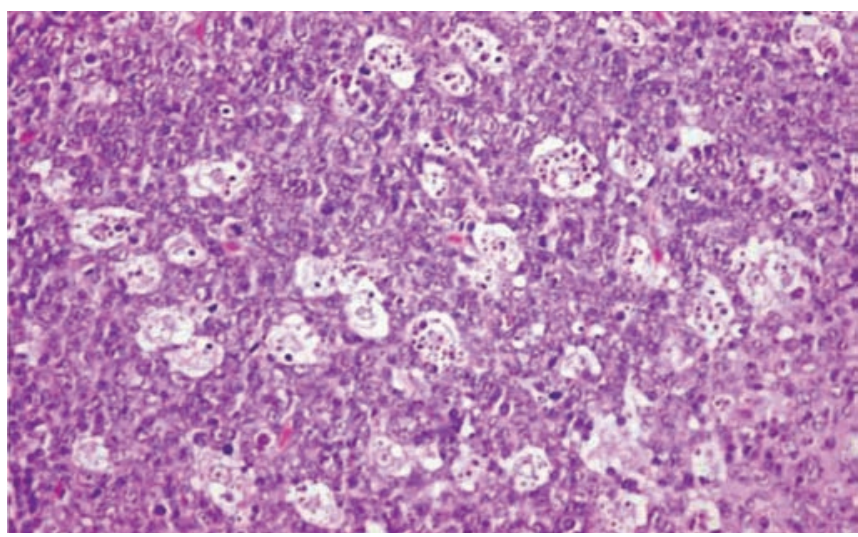

Fig. 1: Photomicrograph of tonsil showing reactive follicular hyperplasia with numerous variable-sized germinal centres with large numbers of tangible body macrophages H\&E 100x
- A total of 45 tonsils from the subjective group were atrophied with a size ranging from 0.5 to $2.0 \mathrm{~cm}$ in diameter.

\section{Microscopic Findings}

- All subjective group and control group revealed reactive follicular hyperplasia with multiple, large, variable-sized, oblong germinal centers occupying the subepithelial tissues. The germinal centers show large dark-stained centroblasts and smaller centrocytes with irregular cleaved nuclear contours together with inconspicuous tangible body macrophages, surrounded by a collar of small resting naive B cells (Fig. 1).

- Twenty-one tonsils (14\%) of 11 subjective patients revealed the picture of Candidiasis with prominent blastopores (Fig. 2).

- Eighteen tonsils (12\%) of 9 subjective patients revealed the picture of Aspergillosis with septate hyphae (Fig. 3A).

- Eight tonsils (5.3\%) of 4 subjective patients revealed the picture of Rhinosporodiosis ${ }^{5}$ with variable-sized cysts (Fig. 3B).

- There was a very little cellular response to the organisms in the form of fewer numbers of mononuclear cells, and scanty proteinaceous debris.

- The adjacent epithelium was normal except for minimal hyperplasia and a small number of neutrophils.

\section{DISCUSSION}

Pathogenic fungi have developed mechanisms to escape and threaten host defenses. Some fungi have evolved as intracellular parasites and can survive within phagocytes by using them to replicate, cause fatal systemic fungal infection, and disseminate throughout the body. Major characteristics of the immune response are the interdependence of various arms of the immune system and the interplay between host defenses and fungal pathogenic mechanisms. Whether the cells use intracellular

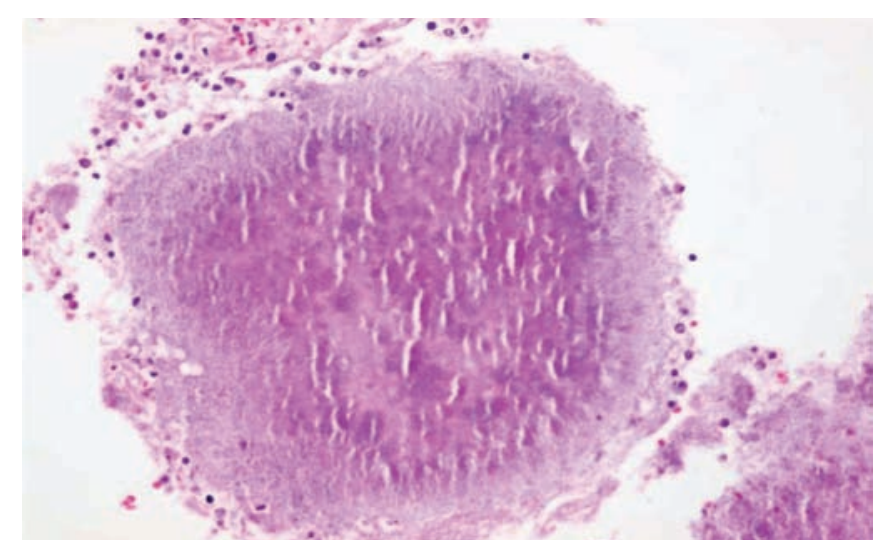

Fig. 2: Photomicrograph of tonsil showing blastopores of Candidal fungal colonies PAS 400x 


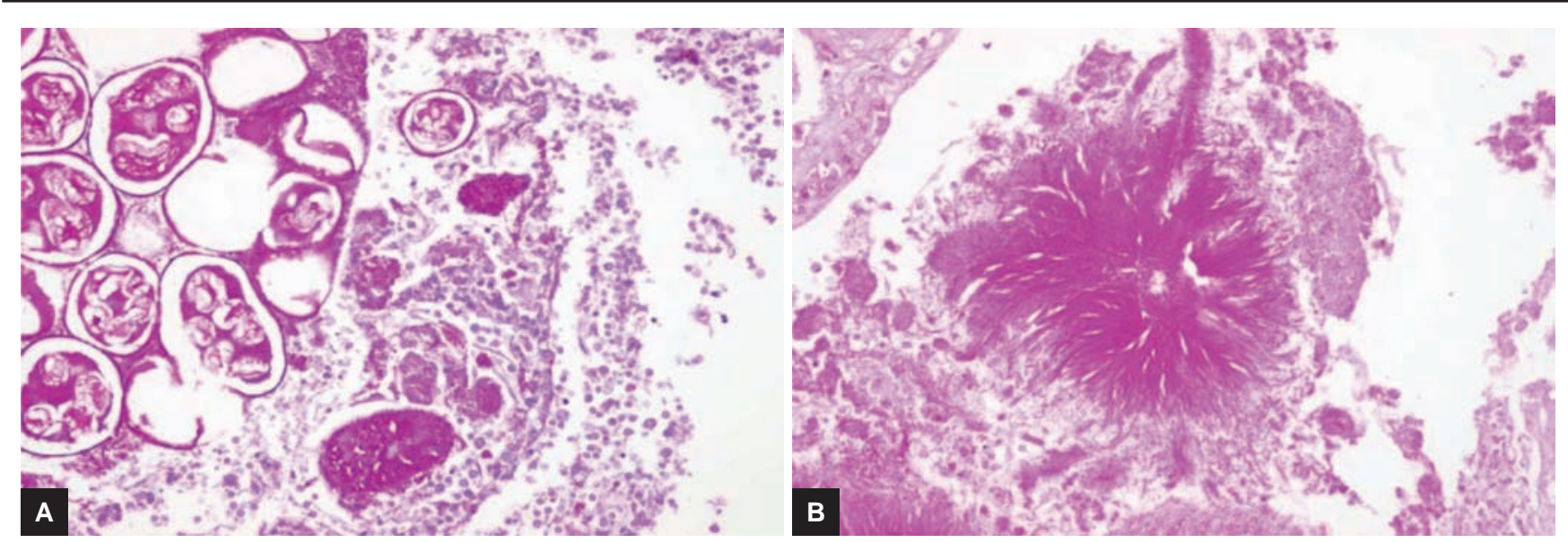

Figs 3A and B: Photomicrograph of tonsil: (A) Showing numerous variable-sized cysts of Rhinosporiodosis fungal colonies, H\&E 400x; and (B) Showing septate hyphae of Aspergillus fungal colonies, PAS 400x

or extracellular antifungal mechanisms depend on the infecting species, morphotype, and route of exposure. ${ }^{6-8}$

Dendritic cells initiate innate and adaptive immunity to a range of microorganisms. ${ }^{9}$ These cells capture and process antigens, express lymphocyte costimulatory molecules, migrate to lymphoid organs, and secrete cytokines to initiate immune response. ${ }^{10}$

Candidiasis is the most common fungal infection of the oral cavity. There are six noncandidal oral infections: Aspergillosis, cryptococcosis, histoplasmosis, blastomycosis, paracoccidioidomycosis, and zygomycosis (mucormycosis). Although these noncandidal fungal infections are considerably less common than oral candidiasis, they commonly produce subclinical infection. ${ }^{11}$

In the present study, presumptive identification of fungal colonies in tonsillar tissue histopathologically with general and specific fungal stains (H\&E and PAC stain) come in agreement with the histopathological results of Maher et $\mathrm{al}^{12}$ but with higher incidence, as $31.3 \%$ of present histopathological study shows tonsillomycosis, 14\% (21 tonsils) shows morphological character of fungal colonies of candidiasis, and $17.3 \%$ (26 tonsils) shows morphological character of fungal colonies represented in: (18 tonsils) $12 \%$ Aspergillosis and (8 tonsils) $5.3 \%$ Rhinosporidiosis. ${ }^{5}$

A number of series have been published to assess the relationship between tonsillar actinomycosis and clinical tonsillar disease. ${ }^{13-17}$ Pransky et $\mathrm{al}^{15}$ found that histological examination of the core tissues of the tonsils accurately detected the presence of these organisms. They found an increased prevalence of actinomycosis in patients undergoing tonsillectomy and postulated that core tissue colonization may be associated with lymphoid hyperplasia and obstructive symptoms. They suggested course of 12 weeks oral penicillin to be administrated to all patients with obstructive symptoms to eradicate the organism and diminish the tonsillar size. Bhargava et a $1^{13}$ similarly found a positive correlation between actinomycosis and tonsillar hypertrophy; actinomycosis was present in $56.8 \%$ of patients with tonsillar hypertrophy compared to $10.3 \%$ of patients with recurrent tonsillitis. ${ }^{7}$ They also found association of tonsillar actinomycosis with sickle cell anemia, beta thalassemia, bronchial asthma, and beta hemolytic streptococcal infections, and suggested tonsillectomy as the treatment of choice for tonsillar actinomycosis. ${ }^{7}$

Thus the present study considers actinomycosis Gram-positive saprophytic bacteria not ray fungus and tonsillar crypts as its normal habitat and is in agreement with recent studies supported by Grüner ${ }^{18}$, i.e., doing histological survey of autopsy material for the prevalence of Actinomyces in normal tonsils. He found Actinomyces colonies in the tonsils of 9 of 22 bodies and suggested that tonsillar crypts were a normal habitat of such colonies.

The present study is in agreement with Jokinen et $\mathrm{al}{ }^{19}$ results as fungal colonies act as antigens that induce epithelial hyperplasia, infiltrated with a few neutrophils without any granulomatous reaction.

Tonsillomycosis is significant in children with hypertrophic tonsils, with the average size $4.8 \mathrm{~cm}$ in diameter, neutropenia in complete blood picture (staff cell from 28 to $48 \%$ ) as neutrophils, macrophages, and monocytes are fundamentally important antifungal effector cells in innate immunity and pathogen recognition. ${ }^{20}$

In management of children with otorhinolaryngological manifestations of systemic bacterial and fungal infections, ORL specialist should be correctly trained to prompt recognition of also uncommon infectious diseases involving head and neck, in order to trigger an integrated otorhinolaryngological, pediatric diagnostic and therapeutic workup as follows: Avoiding predisposing factors: (abuse of antibiotics, dental caries, passive smoking, and malnutrition) the most common local antifungal is oral suspension Nystatin $100.000 \mathrm{u} / \mathrm{mL}$ three times daily for 7 to 14 days while the definite treatment of tonsillomycosis is tonsillectomy. ${ }^{13,21}$

Children with a refractory or recurrent infection are at high risk for systemic disease, or absolute contraindication 
for tonsillectomy should be treated with systemic antifungal but must be performed under safety precaution to hepatotoxic effect. ${ }^{22}$

\section{CONCLUSION}

The observed result is $31.3 \%$ of tonsils (47/150) of 24 subjective patients with photographic illustration revealing morphology of fungal invasion to tonsillar tissue with immune reaction and the presence of chronic inflammatory cells.

After statistical analysis of the collected crude data, including (personal, investigatory and clinical data), the observed result comes in accordance with the previous studies. Tonsillomycosis is mostly accompanied in children with long-term antibiotic administration due to repeated attacks of acute tonsillitis, as it is a slow inflammatory process in these children.

Recent insights suggest that neutrophils, macrophages, and monocytes are fundamentally important antifungal effector cells.

Neutropenia is a definite finding in patients with tonsillomycosis while it may be or may be not found with other causes of chronic tonsillitis.

\section{REFERENCES}

1. Iatta R, Napoli C, Borghi E, Montagna MT. Rare mycoses of the oral cavity. A literature epidemiologic review. Oral Surg Oral Med Oral Pathol Oral Radiol Endod 2009 Nov;108(5):647-655.

2. Akpan A, Morgan R. Oral candidiasis. Postgrad Med J 2002 Aug;78(922):455-459.

3. Wetmore RF. Tonsils and adenoids. In: Kliegman RM, Behrman RE, Jenson HB, Stanton BF, editors. Nelson textbook of paediatrics. 18th ed. Philadelphia (PA): Saunders; 2007.

4. Thuma P. Pharyngitis and tonsillitis. In: Hoekelman RA, editor. Primary paediatric care. St Louis (MO): Mosby; 2001.

5. Chandrashekharayya SH, Suligavi SS, Chougule S, Doddamani SS. Nasal rhinosporidiosis revisited. Clin Rhinol 2010 May-Aug;3(2):73-75.

6. Diamond RD, Krzesicki R, Epstein B, Jao W. Damage to hyphal forms of fungi by human leukocytes in vitro. A possible host defense mechanism in aspergillosis and mucormycosis. Am J Pathol 1978 May;91(2):313-328.

7. Schaffner A, Douglas H, Braude A. Selective protection against conidia by mononuclear and against mycelia by polymorphonuclear phagocytes in resistance to Aspergillus.
Observations on these two lines of defense in vivo and in vitro with human and mouse phagocytes. J Clin Invest 1982 Mar; 69(3):617-631.

8. Kan VL, Bennett JE. Lectin-like attachment sites on murine pulmonary alveolar macrophages bind Aspergillus fumigatus conidia. J Infect Dis 1988 Aug;158(2):407-414.

9. Huang Q, Liu D, Majewski P, Schulte LC, Korn JM, Young RA, Lander ES, Hacohen N. The plasticity of dendritic cell responses to pathogens and their components. Science 2001 Oct 26;294(5543):870-875.

10. Banchereau J, Steinman RM. Dendritic cells and the control of immunity. Nature 1998 Mar 19;392(6673):245-252.

11. Marsot DK, Quillard J, Meyohas MC. Head and neck lesions in the immunocompromised host. Eur Radiol 2004 Mar;14 (Suppl 3):E155-E167.

12. Maher A, Bassiouny A, Bucci TJ, Moawad MK, Hendawy DS. Tonsillomycosis: a myco-histopathological study. J Laryngol Otol 1982 Mar;96(3):229-240.

13. Bhargava D, Bhusnurmath B, Sundaram KR, Raman $R$, Al Okbi HM, Al Abri R, Date A. Tonsillar actinomycosis: a clinicopathlogical study. Acta Trop 2001 Oct 22;80(2):163-168.

14. Melgarejo Moreno P, Hellin Meseguer D, Marco Garrido A, Galindo Ortego X, Ruiz Macia JA, Hostalet F. A correlation between age and Actinomyces in the adenotonsillar tissue in children. B-ENT 2006;2(2):95-97.

15. Pransky SM, Feldman JI, Kearns DB, Seid AB, Billman GF. Actinomycosis in obstructive tonsillar hypertrophy and recurrent tonsillitis. Arch Otolaryngol Head Neck Surg 1991 Aug;117(8):883-885.

16. Aydin A, ErkiliçS, Bayazit YA, Koçer NE, Ozer E, Kanlikama M. Relation between actinomycosis and histopathological and clinical features of the palatine tonsils: a comparative study between adult and paediatric patients. Rev Laryngol Otol Rhinol (Bord) 2005;126(2):95-98.

17. Gaffney R, Harrison M, Walsh M, Sweeney E, Cafferkey M. The incidence and role of Actinomyces in recurrent acute tonsillitis. Clin Otolaryngol Allied Sci 1993 Aug;18(4):268-271.

18. Grüner OPN. Actinomyces in tonsillar tissue. Acta Pathol Microbiol Immunol Scand Sect A 1969 Sep;76(2):239-244.

19. Jokinen K, Pajarre S, Palva A, Sipilä P. Mycotic flora in tonsils and adenoids: a microbiological and histological evaluation J Laryngol Otol 1976 Oct;90(10):945-952.

20. Akira S, Uematsu S, Takeuchi O. Toll-like receptor: pathogen recognition and innate immunity. Cell 2006 Feb 24;124(4): 783-801.

21. Praskash T. Koflet lozenges in the treatment of sore throat. Antiseptic 2001;98(4):124-127.

22. Castagnola E, Machetti M, Bucci B, Viscoli C. Antifungal prophylaxis with azole derivatives. Clin Microbiol Infect 2004 Mar;10(Suppl 1):86-95. 